\title{
A cascade leading to premature aging phenotypes including abnormal tumor profiles in Werner syndrome (Review)
}

\author{
MASANOBU SUGIMOTO \\ GeneCare Research Institute, Co. Ltd., Kamakura, Kanagawa 247-0063, Japan
}

Received September 7, 2013; Accepted December 11, 2013

DOI: $10.3892 /$ ijmm.2013.1592

\begin{abstract}
This perspective review focused on the Werner syndrome (WS) by addressing the issue of how a single mutation in a WRN gene encoding WRN DNA helicase induces a wide range of premature aging phenotypes accompanied by an abnormal pattern of tumors. The key event caused by WRN gene mutation is the dysfunction of telomeres. Studies on normal aging have identified a molecular circuit in which the dysfunction of telomeres caused by cellular aging activates the TP53 gene. The resultant p53 suppresses cell growth and induces a shorter cellular lifespan, and also compromises mitochondrial biogenesis leading to the overproduction of reactive oxygen species (ROS) causing multiple aging phenotypes. As an analogy of the mechanism in natural aging, we described a hypothetical mechanism of premature aging in WS: telomere dysfunction induced by WRN mutation causes multiple premature aging phenotypes of WS, including shortened cellular lifespan and inflammation induced by ROS, such as diabetes mellitus. This model also explains the relatively late onset of the disorder, at approximately age 20 . Telomere dysfunction in WS is closely correlated with abnormality in tumorigenesis. Thus, the majority of wide and complex pathological phenotypes of WS may be explained in a unified manner by the cascade beginning with telomere dysfunction initiated by $W R N$ gene mutation.
\end{abstract}

\section{Contents}

1. Introduction

2. Genomic instability and telomere dysfunction

3. Telomere dysfunction and activation of aging pathway

Correspondence to: Dr Masanobu Sugimoto, GeneCare Research Institute, Co. Ltd., TECOM 2nd Building, 19-2 Kajiwara, Kamakura, Kanagawa 247-0063, Japan

E-mail: masasugi0467@m.jcnnet.jp

Key words: Werner syndrome, telomere, telomere crisis, inflammation, WRN helicase, premature aging, oxidative stress, mitochondria
4. Mitochondrial compromise by telomere dysfunction

5. Increase in oxidative stress in WS

6. Correlation with the target of rapamycin (TOR)

7. Abnormality in tumorigenesis

8. Conclusion

\section{Introduction}

Patients with Werner syndrome (WS) show a wide range of premature aging phenotypes accompanied by rare tumors (1). The major premature aging phenotypes include gray hair, hoarseness, cataract, diabetes and malignancy (Table I). However, phenotypes of WS are not necessarily identical to those of natural aging; for instance WS is not usually accompanied by hearing loss, presbyopia or brain dysfunction, such as Alzheimer's disease and Parkinson's disease $(1,2)$.

$W R N$, the causative gene of WS, is located on human chromosome 8p12-11.2 (3). This gene encodes the WRN protein consisting of 1432 amino acids (4), which acts as a DNA helicase with exonuclease activity (5-7). WRN is a member of the RecQ helicase gene family, which includes RECQL1 (8), Bloom syndrome gene (BLM) (9), WRN (4), Rothmund-Thomson syndrome gene (RTS/RECQL4) (10), and RECQL5 (11). Mutations of BLM,WRN and RTS result in Bloom syndrome (BS), Werner syndrome (WS) and Rothmund-Thomson syndrome (RTS), respectively. These three genetic disorders are associated with genomic instability, and therefore the RecQ helicases are considered to be guardians of the genome (12-14). Diseases caused by mutations of RECQL1 and RECQL5 have yet to be identified.

WS has 100 different mutation types, which result in the early termination of protein synthesis (15). The WRN protein has a nuclear localization signal (NLS) in its C-terminus and is located in the nucleus where it functions. Mutations occur throughout the helicase molecule resulting in truncated polypeptides that lack NLS in the C-terminus (16). Therefore, a mutated WRN in patient cells cannot be transported to the nucleus $(17,18)$.

The mechanism of how the mutation of the single gene $W R N$ induces such multi-phenotypes in WS remains to be determined. This perspective review focused on a hypothetical cascade beginning with telomere dysfunction caused by WRN gene mutation leading to multi-phenotypes of premature aging and an abnormal profile of tumors. 


\section{Genomic instability and telomere dysfunction}

WS somatic cells are characterized by chromosomal aberrations known as 'variegated translocation mosaicism' (19), representing frequent pseudodiploidy with variable and clonal structural rearrangements associated with a high proportion of genomic deletions $(20,21)$. This type of chromosomal aberration is assumed to be closely correlated with premature aging phenotypes, including rare tumors, in WS.

Accelerated loss of telomere repeats was observed in cultured WS patient fibroblasts (22), and recently this phenomenon was also confirmed in vivo by Ishikawa et al (23), who noted an accelerated epidermal telomere loss in WS patient tissues (Fig. 1). Authors of that study analyzed statistically the relationship between WS and control groups by applying a multiple regression model to the data of Fig. 1, and concluded that the lengths of the terminal restriction fragment (TRF) in WS patients were equivalent to those in control individuals who were $\geq 26$ years. Abnormal telomere changes of B-lymphoblastoid cell lines (LCLs) from WS patients transformed by Epstein-Barr virus have also been previously reported (24) (Fig. 2). The telomere length of the majority of LCLs from normal individuals decreases uniformly and most of them no longer proliferate by 160 population doublings, although a very small proportion of them immortalize to continue proliferation (24-27). However, most LCLs obtained from WS patients show irregular changes of telomere length and repeated lengthening and shortening, without the occurrence of immortalized cell lines. We hypothesized (28) that an alternative pathway is involved in maintaining telomeres (29) in order to maintain telomere length in normal and WS LCLs that have relatively long life spans (28) compared with normal fibroblasts (30).

Molecular biological studies support the idea that genomic instability in WS cells is caused directly by telomere dysfunction. WRN helicase is capable of unwinding in vitro duplexed and tetraplexed DNA structures occurring in telomere and ribosomal DNA that are rich in repeated sequences (31). WRN is considered necessary for the efficient replication of G-rich telomere DNA, preventing telomere dysfunction and consequent genomic instability (32). Replication-associated telomere loss is responsible for chromosome fusions found in WS fibroblasts (33).

When the supF shuttle vector (SV) with (TTAGGG)6 as a model of a telomere was used for the mutagenesis assay in order to evaluate the role of WRN protein (34), SV sequences were stably replicated in human cells having normal WRN protein. WRN depletion, however, caused a marked increase (70-fold) in deletions and rearrangements arising within telomere SV. These results suggest that WRN protein contributes to the prevention of large deletions and rearrangements during replication of a telomere sequence, and provides a possible explanation for increased telomere loss and abnormal telomere dynamics in WS cells.

The shelterin complex is formed at telomeres by a group of six proteins including telomeric repeat binding factors TRF1 and TRF2, which assemble along the telomere region and are involved in telomere maintenance and protection (35-37). Of note, WRN is assumed to operate preferentially on aberrant DNA structures believed to exist in vivo, such as replication of forked DNA, Holliday junctions, triplex and tetraplex DNA, and to repair partial duplex with single-stranded bubble (38). WRN has also been shown to cooperate functionally at telomeres with shelterin proteins, including TRF2 (38). Therefore, this evidence strengthens the idea that absence of normal WRN in WS cells may be closely associated with the telomere dysfunction of WS cells.

Telomere dysfunction by an extreme shortening requires a long period of time and therefore, the present hypothesis regarding involvement of telomere dysfunction in WS disorder explains the relatively late onset of its phenotypes (1), at approximately age 20 .

\section{Telomere dysfunction and activation of aging pathway}

WS cells prolong S-phase and other abnormalities in DNA replication (39-41). DNA damage, including telomere dysfunction, arrests cell growth leading to aging (42), and a hypothesis was proposed for natural aging where telomere-based aging is primarily a stem cell defect caused by the activation of p53 and then by the induction of growth arrest, senescence and apoptosis in resident stem and progenitor cells (43). Davis et al (44) investigated the signaling pathways involved in the proliferative life span barriers in WS fibroblasts. Cultured WS fibroblasts undergo senescence after $\sim 20$ population doublings, which was associated with high levels of CdkIs p16 and p21. Of note, senescent WS cells reentered the cell cycle following microinjection of a p53-neutralizing antibody. Davis et al (44) concluded that the strong similarity between signaling pathways triggering cell cycle arrest in WS and normal fibroblasts supports the hypothesis that accelerated loss of telomeres in WS cells also leads to acceleration of a pathway of aging similar to that in normal cells. Therefore, some phenotypes of WS (Table I) may be induced by p53 activation, including growth retardation, alopecia, and hypogonadism, as they all seem to be correlated with cell proliferation.

An essential role of limiting telomeres in the pathogenesis of WS is also supported by experiments using late-generation mice that were null for $W R N$ and TERC (telomerase RNA component) (45): these $T E R C$-null mice have extremely shortened telomeres. These mice manifest phenotypes of WS patients, including premature aging phenotypes and unique tumors.

\section{Mitochondrial compromise by telomere dysfunction}

Additional mechanisms of aging by telomere dysfunction have been suggested. Recent studies using telomerase reverse transcriptase (TERT)-deficient mice with telomere dysfunction showed a marked compromised mitochondrial function $(42,46)$. This mitochondrial change seems to be caused by combined suppression of transcriptional co-activators PGC1 $\alpha$ (proliferator-activated receptor- $\gamma$ coactivator- $1 \alpha$ ) and PGC1 $\beta$ and their downstream targets. This suppression was mediated by the direct binding of $\mathrm{p} 53$ to the promoters of PGC1 $\alpha$ and PGC1 $\beta$. Notably, TERT-deficient mice showed a reduced expression of genes essential for gluconeogenesis, $\beta$-oxidation and defense against reactive oxygen species (ROS) suggesting a mitochondrial compromise. A hypothesis of a telomere-mitochondrion connection was indicated from 
Table I. Major phenotypes of Werner syndrome.

\begin{tabular}{|c|c|c|c|c|}
\hline Phenotypes & $\begin{array}{c}\text { Occurrence } \\
\text { frequency }(\%)\end{array}$ & $\begin{array}{c}\text { Mean } \\
\text { age (years) }\end{array}$ & $\begin{array}{l}\text { Oxidative stress } \\
\text { and inflammation }\end{array}$ & $\begin{array}{c}\text { Suppressed cell } \\
\text { growth }\end{array}$ \\
\hline Growth retardation & 100 & 18.9 & - & Yes \\
\hline Gray hair, alopecia & 100 & 20.1 & Yes (Gray hair) & Yes (alopecia) \\
\hline Hoarseness & 100 & 22.8 & Yes & Yes \\
\hline Skin sclerosis & 100 & 26.4 & Yes & - \\
\hline Cataract & 100 & 31.2 & Yes & - \\
\hline Diabetes mellitus & 70 & 31.5 & Yes & - \\
\hline Skin ulcer & 40 & 34.7 & Yes & Yes \\
\hline Hypogonadism & 80 & 35.6 & Yes & Yes \\
\hline Osteoporosis & 60 & 39.5 & Yes & Yes \\
\hline Immune abnormalities & 80 & 40.0 & Yes & Yes \\
\hline Atherosclerosis & 20 & 40.6 & Yes & - \\
\hline Brain atrophy & 40 & 40.7 & Yes & Yes \\
\hline Malignancy & 20 & 41.3 & Yes & - \\
\hline
\end{tabular}

This table is based on reference (1). Yes, known or suggested; -, unknown.

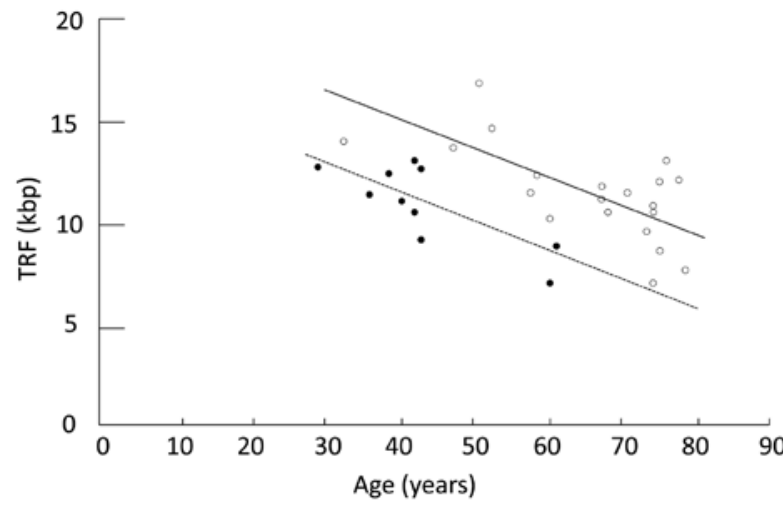

Figure 1. Terminal restriction fragment (TRF) length in skin samples from Werner syndrome (WS) patients and controls. This figure is based on reference (23). $\bullet$, WS patients; $\bigcirc$, controls.

these results (42) that assumes that compromised mitochondrial function causes oxidative stress by increasing ROS levels leading to inflammation and various aging phenotypes. The WRN protein suppresses hypoxia-inducible factor-1 (HIF-1) complex (47). HIF-1 activation in WS cells in the absence of WRN participates in the generation of mitochondrial ROS, Therefore, mitochondrial ROS is considered to be activated in WS cells by a mechanism that includes HIF-1 participation.

Recently, two distinct teams provided evidence that Rothmund-Thomson syndrome (RECQL4) helicases play a role in mitochondrial DNA integrity, which is strongly involved in the aging process $(48,49)$. The role of WRN in mitochondrial function, however, remains to be determined.

\section{Increase in oxidative stress in WS}

Pagano et al (50) suggested participation of oxidative stress in causing WS multi-phenotypes. For instance, they showed an in vivo prooxidant state in WS (51). In this correlation,

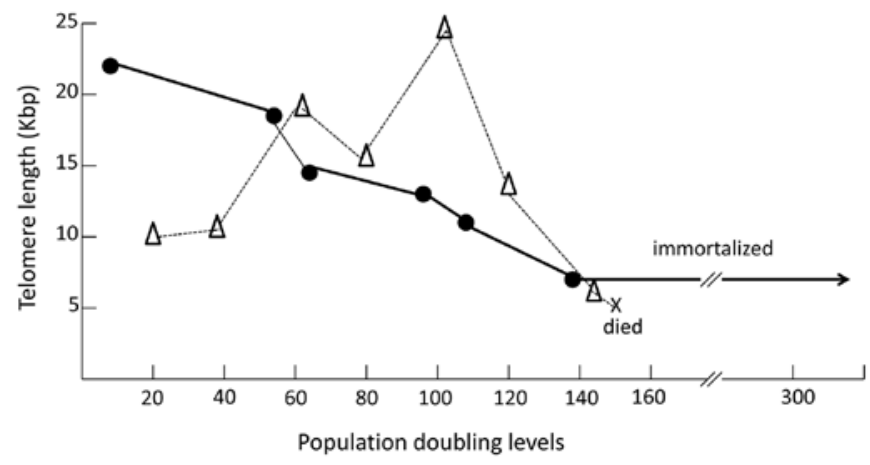

Figure 2. Abnormal telomere changes in B-lymphoblastoid cell lines (LCLs) of Werner syndrome (WS). This figure is based on the figure from reference (28). Cell line WS11301 from a WS patient (dotted line) is mortal LCL with a lifespan of 150 PDL, showing irregular changes of the telomere. The cell line N0003 from a normal individual (solid line) is an immortalized LCL that decreased the telomere length uniformly to 135 PDL and, thereafter is immortalized by expressing high telomerase activity and maintained telomere length.

Goto et al (52) showed that the disulfide glutathione:glutathione ratio was significantly altered in WS patients, glyoxal and methylglyoxal levels significantly increased, and the plasma levels of uric acid $(52,53)$ increased significantly in WS patients. Vitamin $\mathrm{C}$ restored healthy aging phenotypes in a mouse model for Werner syndrome (54).

A significant contribution to human aging of low-grade, chronic and systemic inflammation caused by an imbalance between pro- and anti-inflammatory circuits, mainly by monitoring highly sensitive C-reactive protein (hsCRP), has recently been proposed as inflammaging to explain the aging mechanism (55). Goto et al (56) investigated the inflammatory condition associated with normal human aging by examining hsCRP in sera collected from healthy Japanese individuals and mutation-proven Japanese WS patients. The serum hsCRP level increased significantly with normal aging 
Table II. Neoplasms in Japanese Werner syndrome (1996-2008).

\begin{tabular}{lr}
\hline Diagnosis & No. \\
\hline Non-epithelial & \\
Soft-tissue sarcoma & 8 \\
MFH & 12 \\
Others & 6 \\
Osteosarcoma & 18 \\
Malignant melanoma & 9 \\
Meningioma & \\
Hematologic disorders & 4 \\
AML & 11 \\
MDS & 8 \\
Others & \\
Epithelial & 9 \\
Thyroid & 6 \\
Liver & 5 \\
Skin & 5 \\
Lung & 30 \\
Others & 131 \\
Total & \\
\hline
\end{tabular}

MFH, malignant fibrous histiocytoma; AML, acute myelogenous leukemia; MDS, myelodysplastic syndrome. This table is based on reference (71).

in males and females significantly increased in WS compared with age-matched normal and normal elderly populations. Accordingly, both normal aging and WS were associated with minor inflammation that can be evaluated by serum hsCRP.

Notably, cataract and type-II diabetes mellitus are associated with ROS in non-WS individuals and therefore these two phenotypes of WS may also be associated with ROS. Other phenotypes (Table I), such as gray hair, cataract, diabetes mellitus, skin ulcer and atherosclerosis, of WS may also correlate with ROS $(50,57)$.

Correlated with the association of ROS, oxidative stress markers, including pentosidine and homocysteine, were examined in serum from WS patients and healthy individuals (58). Increased serum pentosidine correlated significantly with normal aging in healthy individuals. Serum pentosidine in WS patients increased significantly compared with age-matched healthy individuals. Serum homocysteine levels increased significantly with normal aging in healthy individuals, but those in WS patients did not increase compared with those from age-matched healthy individuals.

Linkage of increased inflammation and ROS in WS with mitochondrial compromise caused by telomere dysfunction seems likely. Fig. 3 summarizes a hypothetical cascade starting with $W R N$ gene mutation and leading to multi-phenotypes of premature aging in WS patients. A body of data examining the effect of oxidative stress on inflammation by means of modified lipid metabolism has accumulated: for instance, oxidative stress is suggested to cause atherosclerosis and cardiovascular disease by the formation of pro-inflammatory, pro-atherogenic oxidized low-density lipoprotein (59).
Table III. Incidence of immortalization by way of the TCP of LCLs from non-WS and WS individuals.

\begin{tabular}{lccc}
\hline Variables & $\begin{array}{c}\text { Total } \\
\text { LCLs }\end{array}$ & Immortalized & $\%$ of immortalization \\
\hline Non-WS & 61 & 10 & 16.4 \\
WS & 44 & 0 & 0 \\
\hline
\end{tabular}

This table is based on reference (73). Non-WS LCL samples include 11 LCLs from diabetes families showing a high incidence of immortalization $(5 / 11)$ as well as remaining 50 normal LCLs $(5 / 50)$. The Chi-square test of WS LCLs (0/44) against normal individuals (0/50) and the diabetes families (5/11) showed significant differences, $\mathrm{P}<0.031$ and $\mathrm{P}<0.00001$, respectively. TCP, telomere crisis pathway; LCLs, B-lymphoblastoid cell lines; WS, Werner syndrome.

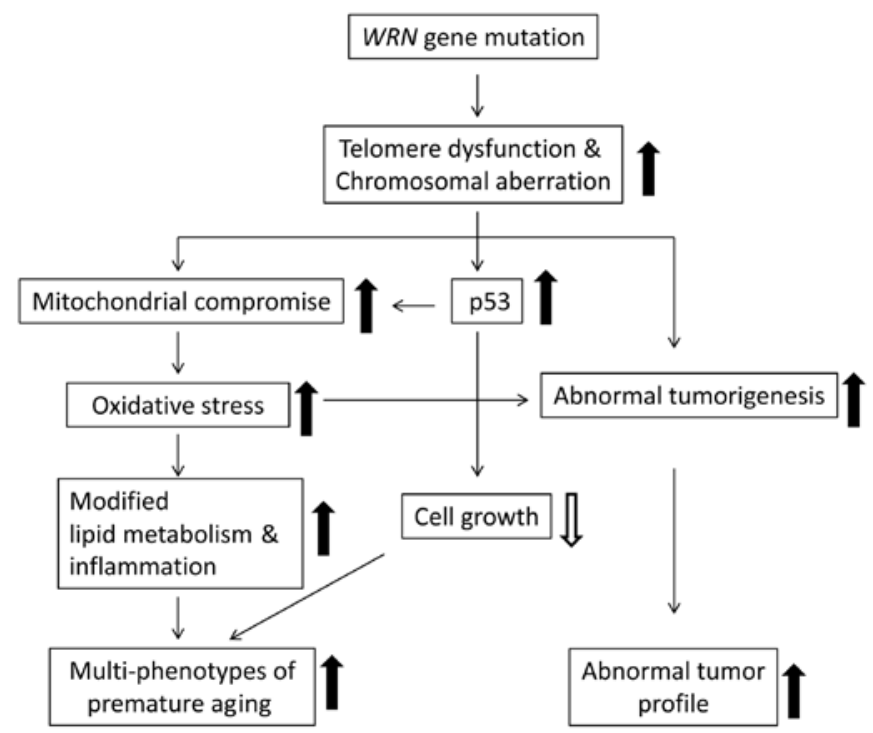

Figure 3. A cascade of Werner syndrome (WS) pathogenesis starting with WRN gene mutation and leading to multi-phenotypes of premature aging and abnormality in tumorigenesis. This scheme does not cover all possible mechanism of the WS pathogenesis but focuses only on the WRN-telomere axis.

WRN plays a role in various functions not mediated by telomeres, such as repair of damaged DNA by genotoxins including camptothecin (60-62) and in the transcription of ribosomal RNA (63). These functions may also be relevant to the premature aging phenotypes of WS. Thus, Fig. 3 shows a major route focusing on the cascade beginning with the WRN-telomere axis.

\section{Correlation with the target of rapamycin (TOR)}

The target of rapamycin (TOR) is a conserved Ser/Thr kinase that regulates cell growth and metabolism in response to environmental cues (64). Inhibition of TOR extends the lifespan of invertebrates as well as of mammals (65-67). In a study conducted to determine whether stressed cells undergo cell death, reversible quiescence or irreversible senescence, $\mathrm{p} 53$ was shown to communicate with the mammalian TOR (mTOR), thereby adding yet another level of complexity to the signaling 
network that emanates from p53 (68). Talaei et al (69) found an increase in cytosolic aggregates in cultured WS fibroblasts and hypothesized that the phenotype is indirectly related to excess activation of the mTOR pathway, leading to the formation of protein aggregates in the cytosol with increasing levels of oxidative stress. As those authors found that the expression levels of the two main $\mathrm{H}_{2} \mathrm{~S}$-producing enzymes, cystathionine $\beta$ synthase and cystathionine $\gamma$ lyase, were lower in WS cells compared with normal cells, they investigated the effect of the administration of $\mathrm{H}_{2} \mathrm{~S}$ by using NaHS $(50 \mu \mathrm{M})$. NaHS treatment blocked mTOR activity, abrogated protein aggregation and normalized the phenotype of WS cells. Similar results were obtained by treatment with mTOR inhibitor rapamycin. These findings suggest the participation of mTOR in the pathogenesis of WS, although p53 activation with the mTOR system remains to be clarified.

\section{Abnormality in tumorigenesis}

Another characteristic feature of WS is a much higher incidence of rare tumors (70). Non-epithelial tumors, including soft-tissue sarcoma and benign meningioma, are highly associated with WS. Notably, the ratio of epithelial (55 cases) to non-epithelial tumors (76 cases) is 1:1.38 in WS patients (Table II) (71) compared with 10:1 in the general population $(70,71)$. Genomic instability and chromosomal aberrations in WS may be the basic phenomenon leading to tumorigenesis, as hypothesized by Monnat (72). WRN helicase was shown to be required for immortalization accompanied by activation of the hTERT gene to activate telomerase by way of the telomere crisis pathway (TCP) in a system that uses LCLs transformed by the Epstein-Barr virus $(62,73)$ (Table III). These data support the hypothesis that the development of TCP-mediated epithelial tumors also requires WRN helicase accompanied by telomerase activation. In non-WS individuals, telomere crisis is considered to produce significant chromosomal instability and thus is a hallmark of human cancer (reviewed in refs. 62,74), such as renal cell carcinoma (75). Whether the assumed inability of tumorigenesis by way of TCP due to WRN dysfunction is associated with an abnormal tumor profile in WS remains to be clarified.

A hypothetical scheme explaining the role of WRN helicase in immortalization by a supposed 'breakage-fusion-bridge cycle' of chromosomes at telomere crisis (76) was suggested in correlation with the unique tumorigenesis profile in WS (77). WRN helicase may have at least two mutually compatible roles in immortalization by way of TCP. First, WRN helicase may unwind the repressed state of chromatin DNA, leading to modification and activation of the promoter region of the hTERT gene (78). Second, in the telomerase-mediated de novo addition of telomeres to non-telomeric sequences generated during the 'breakage-fusion-bridge cycle' (76), the exonuclease activity of WRN helicase may also be involved in this process to trim the $3^{\prime}$ end to expose a favorable sequence as a primer for adding a telomere to the non-telomeric end (79). At this point, particular telomeric repeats may be added by telomerase onto the $3^{\prime}$ end of non-telomeric primers. WRN has been shown to cooperate functionally at telomeres with shelterin proteins, including TRF2 (37), which supports the hypothetical function of WRN in immortalization by way of TCP, as previously suggested (77).

\section{Conclusion}

This perspective review has shown that the majority of wide and complex premature aging phenotypes, including abnormal tumor profiles, of WS may be explained in a unified manner by the cascade beginning with telomere dysfunction initiated by $W R N$ gene mutation, leading to mitochondrial dysfunction and overproduction of ROS.

\section{Acknowledgements}

We would like to thank Dr Yasuhiro Furuichi of the GeneCare Research Institute, Co., Ltd. for his invaluable discussion in the preparation of this manuscript. We would also like to thank Dr Kaiyo Takubo, the Tokyo Metropolitan Institute of Gerontology, for his important input.

\section{References}

1. Goto M and Miller R (eds.): From Premature Gray Hair to Helicase - Werner Syndrome: Implications for Aging and Cancer. Gann Monograph on Cancer Research No 49, Japan Scientific Societies Press \& Karger, Tokyo, 2001.

2. Nishimura F, Arakawa M and Goto M: Letter to the editor: periodontal conditions in Werner syndrome. J Periodontol 81: 3 , 2010.

3. Goto M, Rubenstein M, Weber J, Woods K and Drayna D: Genetic linkage of Werner's syndrome to five markers on chromosome 8. Nature 355: 735-738, 1992.

4. Yu CE, Oshima J, Fu YH, Wijsman EM, Hisama F, Alisch R, Matthews S, Nakura J, Miki T, Ouais S, Martin GM, Mulligan J and Schellenberg GD: Positional cloning of the Werner's syndrome gene. Science 272: 258-262, 1996.

5. Suzuki N, Shimamoto A, Imamura O, Kuromitsu J, Kitao S, Goto $\mathrm{M}$ and Furuichi Y: DNA helicase activity in Werner's syndrome gene product synthesized in a baculovirus system. Nucleic Acids Res 25: 2973-2978, 1997.

6. Suzuki N, Shiratori M, Goto M and Furuichi Y: Werner syndrome helicase contains a $5^{\prime} \rightarrow 3^{\prime}$ exonuclease activity that digests DNA and RNA strands in DNA/DNA and RNA/DNA duplexes dependent on unwinding. Nucleic Acids Res 27: 2361-2368, 1999.

7. Huang S, Li B, Gray MD, Oshima J, Mian IS and Campisi J: The premature ageing syndrome protein, WRN, is a $3^{\prime} \rightarrow 5^{\prime}$ exonuclease. Nat Genet 20: 114-116, 1998.

8. Seki M, Miyazawa H, Tada S, Yanagisawa J, Yamaoka T, Hoshino S, Ozawa K, Eki T, Nogami M and Okumura K: Molecular cloning of cDNA encoding human DNA helicase Q1 which has homology to Escherichia coli $\operatorname{Rec} Q$ helicase and localization of the gene at chromosome 12p12. Nucleic Acids Res 22: 4566-4573, 1994.

9. Ellis NA, Groden, J, Ye TZ, Straughen J, Lennon DJ, Ciocci S, Proytcheva M and German J: The Bloom's syndrome gene product is homologous to RecQ helicases. Cell 83: 655-666, 1995.

10. Kitao S, Shimamoto A, Goto M, Miller RW, Smithson WA, Lindor NM and Furuichi Y: Mutations in RECQL4 cause a subset of cases of Rothmund-Thomson syndrome. Nat Genet 22: 82-84, 1999.

11. Shimamoto A, Nishikawa K, Kitao S and Furuichi Y: Human RecQ5beta, a large isomer of RecQ5 DNA helicase, localizes in the nucleoplasm and interacts with topoisomerases 3alpha and 3beta. Nucleic Acids Res 28: 1647-1655, 2000.

12. Shimamoto A, Sugimoto M and Furuichi Y: Molecular biology of Werner syndrome. Int J Clin Oncol 9: 288-298, 2004.

13. Bohr VA: Rising from the RecQ-age: the role of human RecQ helicases in genome maintenance. Trends Biochem Sci 33: 609-620, 2008.

14. Goto M: Syndrome-causing mutations in Werner syndrome. Biosci Trends 2: 147-150, 2008.

15. Goto M, Imamura O, Kuromitsu J, Matsumoto T, Yamabe Y, Tokutake Y, Suzuki N, Mason B, Drayna D, Sugawara M, Sugimoto M and Furuichi Y: Analysis of helicase gene mutations in Japanese Werner's syndrome patients. Hum Genet 99: 191-193, 1997. 
16. Goto M, Yamabe M, Shiratori M, Okada M, Kawabe T, Matsumoto T, Sugimoto M and Furuichi Y: Immunological diagnosis of Werner syndrome by down-regulated and truncated gene products. Hum Genet 105: 301-307, 1999.

17. Matsumoto T, Shimamoto A, Goto M and Furuichi Y: Impaired nuclear localization of defective DNA helicases in Werner's syndrome. Nat Genet 16: 335-336, 1997.

18. Matsumoto $T$, Imamura $O$, Goto $M$ and Furuichi $Y$ : Characterization of the nuclear localization signal in the DNA helicase involved in Werner's syndrome. Int J Mol Med 1: 71-76, 1998.

19. Salk D, Au K, Hoehn H and Martin GM: Cytogenetics of Werner's syndrome cultured skin fibroblasts: variegated translocation mosaicism. Cytogenet Cell Genet 30: 92-107, 1981

20. Fukuchi K, Martin GM and Monnat RJ Jr: Mutator phenotype of Werner syndrome is characterized by extensive deletions. Proc Natl Acad Sci USA 86: 5893-5897, 1989.

21. Gebhart E, Bauer R, Raub U, Schinzel M, Ruprecht KW and Jonas JB: Spontaneous and induced chromosomal instability in Werner syndrome. Hum Genet 80: 135-139, 1988.

22. Schulz VP, Zakian VA, Ogburn CE, McKay J, Jarzebowicz AA, Edland SD and Martin GM: Accelerated loss of telomeric repeats may not explain accelerated replicative decline of Werner syndrome cells. Hum Genet 97: 750-754, 1996.

23. Ishikawa $N$, Nakamura $K$, Izumiyama-Shimomura $N$, Aida J, Ishii A, Goto M, Ishikawa Y, Asaka R, Matsuura M, Hatamochi A, Kuroiwa M and Takubo K: Accelerated in vivo epidermal telomere loss in Werner syndrome. Aging (Albany NY) 3: 417-429, 2011.

24. Tahara H, Tokutake Y, Maeda S, Kataoka H, Watanabe T, Satoh M, Matsumoto T, Sugawara M, Ide T, Goto M, Furuichi Y and Sugimoto M: Abnormal telomere dynamics of B-lymphoblastoid cell strains from Werner's syndrome patients transformed by Epstein-Barr virus. Oncogene 15: 1911-1920, 1997.

25. Counter CM, Botelho FM, Wang P, Harley CB and Bacchetti S: Stabilization of short telomeres and telomerase activity accompany immortalization of Epstein-Barr virus-transformed human B lymphocytes. J Virol 68: 3410-3414, 1994.

26. Sugimoto M, Tahara H, Ide T and Furuichi Y: Steps involved in immortalization and tumorigenesis in human B-lymphoblastoid cell lines transformed by Epstein-Barr virus. Cancer Res 64: 3361-3364, 2004

27. Sugimoto M, Ide T, Goto M and Furuichi Y: Incorrect use of 'immortalization' for B-lymphoblastoid cell lines transformed by Epstein-Barr virus. J Virol 73: 9690-9691, 1999.

28. Sugimoto M, Ide T, Goto M and Furuichi Y: Reconsideration of senescence, immortalization and telomere maintenance of Epstein-Barr virus-transformed human B-lymphoblastoid cell lines. Mech Ageing Dev 107: 51-60, 1999

29. Bryan TM, Englezou A, Dalla-Pozza L, Dunham MA and Reddel RR: Evidence for an alternative mechanism for maintaining telomere length in human tumors and tumor-derived cell lines. Nat Med 3: 1271-1274, 1997.

30. Hayflick L: The limited in vitro lifetime of human diploid cell strains. Exp Cell Res 37: 614-636, 1965.

31. Fry M and Loeb LA: Human werner syndrome DNA helicase unwinds tetrahelical structures of the fragile $X$ syndrome repeat sequence d(CGG)n. J Biol Chem 274: 12797-12802, 1999.

32. Crabbe L, Verdun RE, Haggblom CI and Karlseder J: Defective telomere lagging strand synthesis in cells lacking WRN helicase activity. Science 306: 1951-1953, 2004.

33. Crabbe L, Jauch A, Naeger CM, Holtgreve-Grez $\mathrm{H}$ and Karlseder J: Telomere dysfunction as a cause of genomic instability in Werner syndrome. Proc Natl Acad Sci USA 104 2205-2210, 2007.

34. Damerla RR, Knickelbein KE, Strutt S, Liu FJ, Wang H and Opresko PL: Werner syndrome protein suppresses the formation of large deletions during the replication of human telomeric sequences. Cell Cycle 11: 3036-3044, 2012.

35. de Lange T: Shelterin: the protein complex that shapes and safeguards human telomeres. Genes Dev 19: 2100-2110, 2005.

36. Palm $\mathrm{W}$ and de Lange T: How shelterin protects mammalian telomeres. Annu Rev Genet 42: 301-334, 2008

37. Diotti R and Loayza D: Shelterin complex and associated factors at human telomeres. Nucleus 2: 119-135, 2011.

38. Ozgenc A and Loeb LA: Current advances in unraveling the function of the Werner syndrome protein. Mutat Res 577: $237-251,2005$

39. Fujiwara Y, Higashikawa $\mathrm{T}$ and Tatsumi M: A retarded rate of DNA replication and normal level of DNA repair in Werner's syndrome fibroblasts in culture. J Cell Physiol 92: 365-374, 1977.
40. Hanaoka F, Yamada M, Takeuchi F, Goto M, Miyamoto T and Hori T: Autoradiographic studies of DNA replication in Werner's syndrome cells. Adv Exp Med Biol 190: 439-457, 1985.

41. Poot M, Hoehn H, Runger TM and Martin GM: Impaired S-phase transit of Werner syndrome cells expressed in lymphoblastoid cell lines. Exp Cell Res 202: 267-273, 1992.

42. Sahin E and DePinho RA: Axis of ageing: telomeres, p53 and mitochondria. Nat Rev Mol Cell Biol 13: 397-404, 2012.

43. Sharpless NE and DePinho RA: Telomeres, stem cells, senescence, and cancer. J Clin Invest 113: 160-168, 2004.

44. Davis T, Faragher RG, Jones CJ and Kipling D: Investigation of the signaling pathways involved in the proliferative life span barriers in werner syndrome fibroblasts. Ann NY Acad Sci 1019: 274-277, 2004.

45. Chang S, Multani AS, Cabrera NG, Naylor ML, Laud P, Lombard D, Pathak S, Guarente L and DePinho RA: Essential role of limiting telomeres in the pathogenesis of Werner syndrome. Nat Genet 36: 877-882, 2004.

46. Sahin E, Colla S, Liesa M, et al: Telomere dysfunction induces metabolic and mitochondrial compromise. Nature 470: 359-365, 2011.

47. Labbe A, Lafleur VN, Patten DA, Robitaille GA, Garand C, Lamalice L, Lebel $\mathrm{M}$ and Richard DE: The Werner syndrome gene product (WRN): a repressor of hypoxia-inducible factor-1 activity. Exp Cell Res 318: 1620-1632, 2012.

48. Croteau DL, Rossi ML, Canugovi C, Tian J, Sykora P, Ramamoorthy $M$, Wang ZM, Singh DK, Akbari M, Kasiviswanathan R, Copeland WC and Bohr VA: RECQL4 localizes to mitochondria and preserves mitochondrial DNA integrity. Aging Cell 11: 456-466, 2012.

49. De S, Kumari J, Mudgal R, Modi P, Gupta S, Futami K, Goto H, Lindor NM, Furuichi Y, Mohanty D and Sengupta S: RECQL4 is essential for the transport of p53 to mitochondria in normal human cells in the absence of exogenous stress. J Cell Sci 125 (Pt 10): 2509-2522, 2012.

50. Pagano G, Zatterale A, Degan P, d'Ischia M, Kelly FJ, Pallardo FV and Kodama S: Multiple involvement of oxidative stress in Werner syndrome phenotype. Biogerontology 6: 233-243, 2005

51. Pagano G, Zatterale A, Degan P, d'Ischia M, Kelly FJ, Pallardo FV, Calzone R, Castello G, Dunster C, Giudice A, Kilinc Y, Lloret A, Manini P, Masella R, Vuttariello E and Warnau M: In vivo prooxidant state in Werner syndrome (WS): results from three WS patients and two WS heterozygotes. Free Radic Res 39: 529-533, 2005.

52. Goto M, Takeuchi F, Tanimoto K, Miyamoto T: Clinical, demographic, and genetic aspects of the Werner syndrome in Japan. In: Werner's Syndrome and Human Aging. Advances in Experimental Medicine and Biology. Volume 190. Salk D, Fujiwara Y and Martin GM (eds.). Plenum Press, New York, pp245-261, 1985

53. Takeuchi F, Kamatani N, Goto M, Matsuta K, Nishida Y, Sasaki S, Nishioka K, Mikanagi K, Tanimoto K, Muranaka M and Miyamoto T: Gout-like arthritis in patients with Werner's syndrome. Jap J Rheumatol 1: 215-220, 1987.

54. Massip L, Garand C, Paquet ER, Cogger VC, O'Reilly JN, Tworek L, Hatherell A, Taylor CG, Thorin E, Zahradka P, Le Couteur DG and Lebel M: Vitamin C restores healthy aging in a mouse model for Werner syndrome. FASEB J 24: 158-172, 2010.

55. Goto M: Inflammaging (inflammation + aging): a driving force for human aging based on an evolutionarily antagonistic pleiotropy theory? Biosci Trends 2: 218-230, 2008.

56. Goto M, Sugimoto K, Hayashi S, Ogino T, Sugimoto M, Furuichi Y, Matsuura M, Ishikawa Y, Iwaki-Egawa S and Watanabe Y: Aging-associated inflammation in healthy Japanese individuals and patients with Werner syndrome. Exp Gerontol 47: 936-939, 2012.

57. Davis T, Wyllie FS, Rokicki MJ, Bagley MC and Kipling D: The role of cellular senescence in Werner syndrome: toward therapeutic intervention in human premature aging. Ann NY Acad Sci 1100: 455-469, 2007.

58. Goto M, Iwaki-Egawa S and Watanabe Y: Ageing in Werner syndrome. Biosci Trends 6: 33-37, 2012.

59. Kaplan M and Aviram M: Oxidized low density lipoprotein: atherogenic and proinflammatory characteristics during macrophage foam cell formation. An inhibitory role for nutritional antioxidants and serum paraoxonase. Clin Chem Lab Med 37: 777-787, 1999. 
60. Lebel $\mathrm{M}$ and Leder P: A deletion within the murine Werner syndrome helicase induces sensitivity to inhibitors of topoisomerase and loss of cellular proliferative capacity. Proc Natl Acad Sci USA 95: 13097-13102, 1998.

61. Okada M, Goto M, Furuichi Y and Sugimoto M: Differential effects of cytotoxic drugs on mortal and immortalized Blymphoblastoid cell lines from normal and Werner's syndrome patients. Biol Pharm Bull 21: 235-239, 1998.

62. Futami K, Ishikawa Y, Goto M, Furuichi Y and Sugimoto M: Role of Werner syndrome gene product helicase in carcinogenesis and in resistance to genotoxins by cancer cells. Cancer Sci 99: 843-848, 2008.

63. Shiratori M, Suzuki T, Itoh C, Goto M, Furuichi Y and Matsumoto T: WRN helicase accelerates the transcription of ribosomal RNA as a component of an RNA polymerase I-associated complex. Oncogene 21: 2447-2454, 2002.

64. Wullschleger S, Loewith R and Hall MN: TOR signaling in growth and metabolism. Cell 124: 471-484, 2006.

65. Blagosklonny MV and Hall MN: Growth and aging: a common molecular mechanism. Aging (Albany NY) 1: 357-362, 2009

66. Harrison DE, Strong R, Sharp ZD, Nelson JF, Astle CM, Flurkey K, Nadon NL, Wilkinson JE, Frenkel K, Carter CS, Pahor M, Javors MA, Fernandez E and Miller RA: Rapamycin fed late in life extends lifespan in genetically heterogeneous mice. Nature 460: 392-395, 2009.

67. Sharp ZD: Aging and TOR: interwoven in the fabric of life. Cell Mol Life Sci 68: 587-597, 2011.

68. Galluzzi L, Kepp O and Kroemer G: TP53 and MTOR crosstalk to regulate cellular senescence. Aging (Albany NY) 2: 535-537, 2010 .

69. Talaei F, van Praag VM and Henning RH: Hydrogen sulfide restores a normal morphological phenotype in Werner syndrome fibroblasts, attenuates oxidative damage and modulates mTOR pathway. Pharmacol Res 74: 34-44, 2013.
70. Goto M, Miller RW, Ishikawa Y and Sugano H: Excess of rare cancers in Werner syndrome (adult progeria). Cancer Epidemiol Biomarkers Prev 5: 239-246, 1996.

71. Goto M, Ishikawa Y, Sugimoto M and Furuichi Y: Werner syndrome: a changing pattern of clinical manifestations in Japan (1917-2008). Biosci Trends 7: 13-22, 2013.

72. Monnat RJ Jr: Cancer pathogenesis in the human RecQ helicase deficiency syndromes. In: From Premature Gray Hair to Heicase - Werner Syndrome: Implications from Aging and Cancer. Goto M and Miller RW (eds.). Basel, pp83-94, 2001.

73. Sugimoto M, Tahara H, Okubo M, Kobayashi T, Goto M, Ide T and Furuichi Y: WRN gene and other genetic factors affecting immortalization of human B-lymphoblastoid cell lines transformed by Epstein-Barr virus. Cancer Genet Cytogenet 152: 95-100, 2004

74. Greenberg RA: Telomeres, crisis and cancer. Curr Mol Med 5: 213-218, 2005.

75. Castro-Vega LJ, Jouravleva K, Liu WY, Martinez C, Gestraud P, Hupe P, Servant N, Albaud B, Gentien D, Gad S, Richard S, Bacchetti S and Londono-Vallejo A: Telomere crisis in kidney epithelial cells promotes the acquisition of a microRNA signature retrieved in aggressive renal cell carcinomas. Carcinogenesis 34: 1173-1180, 2013

76. Ishikawa F: Telomere crisis, the driving force in cancer cell evolution. Biochem Biophys Res Commun 230: 1-6, 1997.

77. Sugimoto M, Furuichi Y, Ide T and Goto M: Involvement of WRN helicase in immortalization and tumorigenesis by the telomeric crisis pathway (Review). Oncol Lett 2: 609-611, 2011.

78. Zhu J, Zhao Y and Wang S: Chromatin and epigenetic regulation of the telomerase reverse transcriptase gene. Protein Cell 1 22-32, 2010.

79. Wang $\mathrm{H}$ and Blackburn $\mathrm{EH}$ : De novo telomere addition by Tetrahymena telomerase in vitro. EMBO J 16: 866-879, 1997. 